\title{
Biometrical analysis of Helicoverpa armigera (Hübner) Hardwick on pigeonpea
}

\author{
S.G. KHORASIYA, H.J. VYAS, D.M. JETHA* AND P.H. JOSHI
}

Department of Entomology, College of Agriculture, Junagadh Agricultural University, JUNAGARH (GUJARAT) INDIA

\section{ARITCLE INFO \\ Received : 26.03 .2014 \\ Revised : 15.08 .2014 \\ Accepted : 29.08.2014}

\section{KEY WORDS :}

Helicoverpa armigera, Biometrical analysis, Pigeonpea
*Corresponding author: Email:dr_dharmraj@yahoo.co.in

\begin{abstract}
Studies on biometrical analysis were carried out at Junagadh Agricultural University campus, Junagadh (Gujarat) during 2006-07 to test the applicability of Dyar's law to the larvae of $H$. armigera, when reared on pigeonpea variety BDN-2 at a constant temperature of $28 \pm 1^{\circ} \mathrm{C}$ in BOD incubator. The measurements of head capsule width of the larvae fell into six well defined groups each indicating an instar. The mean values of the observed ( 0.285 to 2.657 $\mathrm{mm})$ and calculated head capsule width $(0.287$ to $2.819 \mathrm{~mm})$ and progression factors were closed to each other which indicated that an increase in head width during successive instar was in geometrical progression, when larvae were reared on pigeonpea and it followed the Dyar's law. The observed mean body length and width ranged from 1.712 to $28.378 \mathrm{~mm}$ and 0.306 to 3.643 , respectively, for first to six instars on pigeonpea. The observed and estimated progression factors for the larval body length and width passed through six instars were 1.77 and 1.75 and 1.66 and 1.63, respectively. The progression factors determined from body length and width indicated the great deviation to provide any support for the theory suggested by Przibram's and Megusar law. The multiple correlation co-efficient $\left(\mathrm{R}^{2}=0.9996\right)$ also indicated a very high predictability of head capsule width through larval body length and width.
\end{abstract}

How to view point the article : Khorasiya, S.G., Vyas, H.J., Jethva, D.M. and Joshi, P.H. (2014). Biometrical analysis of Helicoverpa armigera (Hübner) Hardwick on pigeonpea. Internat. J. Plant Protec., 7(2) : 393-396. 